\title{
Study on Body Balance in Hypertensive Patients
}

\section{Antonia Dalla Pria Bankoff}

Posture Assessment Laboratory - FEF-Unicamp, Cidade Universitaria - Campinas/SP, Brazil

\begin{abstract}
Body balance data was collected using an electronic baropodometer with a modular platform by Physical Support Italy, in the Electromyography and Posture Biomechanics Laboratory of the School of Physical Education, University of Campinas (Unicamp). The following three groups were studied: group 01, comprised of 15 male hypertensive subjects who take antihypertensive medication; group 02, comprised of 16 male hypertensive subjects; and group 03, comprised of 14 non-hypertensive subjects. The average age of the participants was 52.7 years. The experimental part of the study was conducted under two conditions: bipodalic and monopodalicic, both static. In both conditions, the subjects were barefoot and performed the test first with eyes open, then with eyes closed. In both cases, the equipment was calibrated to 05 seconds for the procedures. Swaying along axes $X$ and $Y$ was recorded in centimeters.

Results: Statistical analysis used analysis of variance, two-factor ANOVA without replication $p<0.05$. The results were significant for the group with hypertensive and hypertensive medication for bipodalic posture. There was no significant difference in variables between the bipodalic posture open and closed eyes. There was significant difference in the posture monopodalic right foot to the hypertensive group on drugs in the $X$ and $Y$ axes eyes closed and the hypertensive group in the $X$ axis right foot eyes closed. The results were also significant for posture monopodalic left foot to the hypertensive group with hypertensive medication and $X$-axis eyes open and eyes closed. There was no significant difference between open and closed eyes. The differences were always in relation to the axes $X$ and $Y$. Conclusion: The antihypertensive medication 30 minutes after being ingested associated with high blood pressure (group 01) and only high levels of blood pressure (group 02) change can cause the body balance the risk of falls in people.
\end{abstract}

Keywords: Body Balance; Hypertension; Antihypertensive; Baropodometry

\section{Introduction}

\section{Body balance}

No data in the literature that high blood pressure and antihypertensive drug intake influence and change the state of equilibrium in the human body. However, subjects with hypertension and those who take antihypertensive drugs reported feelings of risk of falls especially in the morning due to change in body balance [5]. For the body balance is required to be kept a set of functionally interlocking structures: the vestibular system, visual system, proprioceptive system and the environment. Maintaining balance is generally conducted by the vestibular system, it is to detect the sensations of balance. Guidetti [9] reports that human beings, almost despise the ability of the vestibular system, and put almost all the responsibility on the balance visual system. Consequently, even an everyday behavior such as maintaining an erect position is an intricate task which involves a complex association of sensorial information and motor activity [6].

Body balance depends on the integrity of the vestibular system, the somatosensory system and visual. Any change in these functions may change the balance of the individual body and compromise its ability to respond to environmental sounds and maintain a communication is not effective with the environment [17].

Bankoff [1-4] reports an association between balance and postural positions, with postural balance being modified within milliseconds. Regarding balance and maintenance of postural balance, small differences are significant due to swaying in a person's gait and static postures.

Measuring and recording the swaying of the human body while in body balance is known as stabilometry, also called stabilography or statokinesiography. When a person is still, he or she sways, rather than being motionless [9].

For static body balance to be maintained, one must engage a group of functionally intertwined structures: the vestibular system, the eyes and the proprioceptive system. General balance is maintained by the vestibular system, which detects the sensations pertaining to equilibrium. This system is comprised of bony tubes and chambers in the petrous part of the temporal bone, known as the bony labyrinth, in which there is a system of membranous tubes and chambers known as the membranous labyrinth. The latter is the functional part of the vestibular system [10].

The vestibulocochlear nerve - also known as the statoacoustic nerve - is the eighth cranial nerve. It splits into two divisions: one anterior (cochlear nerve) and one posterior (vestibular nerve) [8]. Bear et al. [7] affirm that the primary vestibular axons of the eighth cranial nerve connect directly to the vestibular nuclei, which also receive afferent input from other parts of the nervous system, including the cerebellum and the somatic and visual sensory systems.

The cerebellum has a regulating effect on muscular activities and receives impulses originated from receptors in the joints, tendons, muscles, skin, and also the terminal organs of the visual, auditory and vestibular systems. These impulses are not

*Corresponding author: Antonia Dalla Pria Bankoff, Posture Assessment Laboratory -FEF, University of Campinas (Unicamp), Brazil, E-mail: bankoff@fef.unicamp.br

Received December 07, 2011; Accepted January 11, 2012; Published January 14,2012

Citation: Bankoff ADP (2012) Study on Body Balance in Hypertensive Patients. J Hypertens 1:101. doi:10.4172/2167-1095.1000101

Copyright: $\odot 2012$ Bankoff ADP. This is an open-access article distributed under the terms of the Creative Commons Attribution License, which permits unrestricted use, distribution, and reproduction in any medium, provided the original author and source are credited. 
conscious, but are essential stimuli in the control of movement [11]. Bankoff [2] reports the existence of reflex sensitivity associated with eye speed during the gait movements involved in human locomotion. This sensitivity is directly associated with the maintenance of body balance, which requires information from external sensory receptors, such as those in the feet, to maintain the tonic postural system $[15,16]$. The decline in postural stability leads losses occurred due to falls and their consequent fractures and assets, making the individual to lose their autonomy and consequently, decrease their quality of life. From early adulthood until the year intermediaries, and sensory changes motor is small and gradual, almost unnoticeable. From the age of 45 , these changes become more pronounced, reaching the sensory systems (visual, vestibular and somatosensory) and capabilities motor as strength, flexibility, time reaction, balance and coordination, thus making the elderly the most affected by balance problems.

There are several factors that lead individuals to change the body balance (labyrinthitis, loud noises and constant neck pain, intake of antihypertensive medication, high blood pressure, inactivity and others [5].

\section{Arterial hypertension}

Arterial pressure is not regulated by a single pressure controlling system, but rather by several interrelated systems that perform specific functions. There are two main types of systems that control arterial pressure in the human body: fast-acting mechanisms and long-term mechanisms that control the basic level of arterial pressure. The fast-acting pressure control mechanisms work through nervous or hormonal control of blood circulation. The hormonal mechanisms, specially the hormone angiotensin, also respond quickly to blood pressure changes. These responses help to bring arterial pressure back to normal. Although the nervous regulators of arterial pressure act very quickly and effectively to correct acute abnormalities in blood pressure, they usually lose their effectiveness after a few hours or days because the pressure receptors "ADAPT", i.e., they lose their responsiveness.

On the other hand, the long-term blood pressure regulation system controls pressure via fluid excretion by the kidneys. This system operates basically as follows: when arterial pressure drops, the kidneys retain water and salts until the volume of blood increases. This, in turn, raises arterial pressure back to normal.

\section{Role of baroreceptors in posture changes}

The ability of the human body's baroreceptors to keep arterial blood pressure relatively constant is very important when a person sits up or stands up from a lying position. Immediately after standing up, arterial blood pressure in the head and upper body tends to drop, and an abrupt reduction of this pressure can lead to loss of consciousness. However, when the baroreceptors detect a pressure drop, an immediate reflex fires a strong sympathetic response throughout the body and mitigates the pressure drop in the head and upper body [10]. This command is also important for the maintenance of body posture with the cochlear and vestibular system and cerebellum.

Arterial hypertension is characterized as blood pressure levels above $140 \times 90 \mathrm{mmHg}$ (millimeters of mercury) in adults above age 18 , measured at fifteen minutes of rest and confirmed after three consecutive measurements. Occasional spikes in blood pressure may occur under some circumstances such as physical activity, anger, anxiety, and the ingestion of drugs, some types of food, tobacco, alcohol, or coffee.

\section{Chart-Blood pressure levels}

\begin{tabular}{|l|l|l|}
\hline SYSTOLIC & DIASTOLIC & LEVEL \\
\hline$<130$ & $<85$ & Normal \\
\hline $130-139$ & $85-89$ & Borderline normal \\
\hline $140-159$ & $90-99$ & Mild hypertension \\
\hline $160-179$ & $100-109$ & Moderate hypertension \\
\hline$>179$ & $>109$ & Severe hypertension \\
\hline
\end{tabular}

\section{Medications}

The association of antihypertensive drugs which are indicated for patients with arterial hypertension is a consummate fact. These drugs are prescribed for ingestion immediately after breakfast. Among the most commonly prescribed drugs are: Hydrochlorothiazide $50 \mathrm{mg}$, Furosemide $40 \mathrm{mg}$, Methyldopa 250mg, Nifedipine 20mg, Propranolol $40 \mathrm{mg}$, and Captopril $25 \mathrm{mg}$.

The labels of these medications reveal that they can cause dizziness and fainting. They also recommend that the patient stand up slowly during the first days of treatment. These effects of the aforementioned drugs are associated with a reduction or loss of body balance over a period of the patient's life, specifically in the morning, when the day is starting and the patient needs all of his or her energy for the day's activities. The body's own system of baroreceptors shows their effect on changes in body posture.

SURFACE

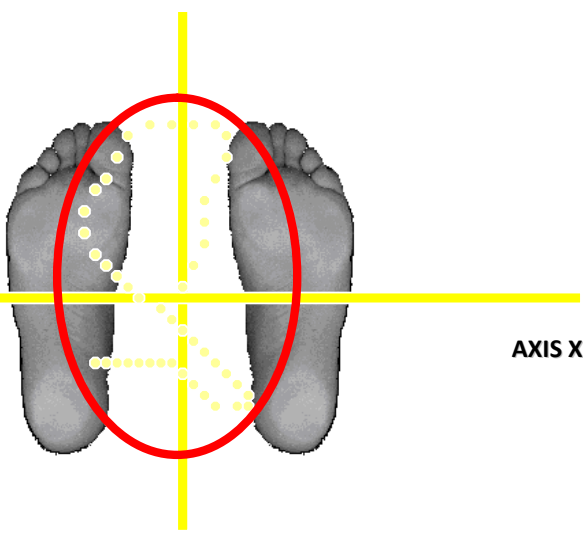

AXIS Y

Figure 1: Analysis stabilometric.

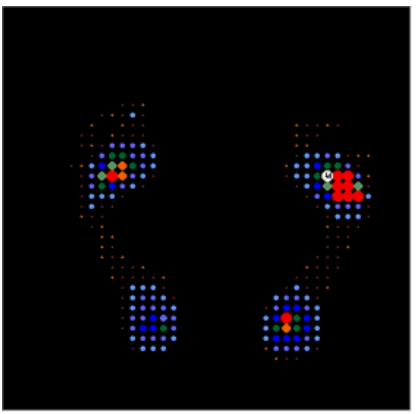

Figure 2: Example of analysis baropodometric bipodalic posture. 


\section{General Objective}

To study static body balance in subjects with arterial hypertension and in hypertensive patients under the influence of antihypertensive drugs, in bipodalic and monopodalicic posture, using electronic baropodometry.

\section{Specific objectives}

- To examine the influence of antihypertensive medication on the control of bipodalic and monopodalicic body balance in hypertensive subjects;

- To examine the influence of arterial hypertension on the control of body balance in hypertensive subjects that do not take antihypertensive drugs;

- To analytically compare monopodalicic and bipodalic stabilometry;

- To examine bipodalic and monopodalicic swaying in relation to axes $\mathrm{X}$ and $\mathrm{Y}$.

\section{Methodology}

The methodology employed in this study was data collection via an Electronic Baropodometer. The research was performed in the Electromyography and Posture Biomechanics Laboratory of the School of Physical Education, State University of Campinas - Unicamp.

\section{Subjects}

The study was performed on three groups of male subjects, namely: group $01=15$ hypertensive subjects who take antihypertensive medication (Captopril); group $02=16$ hypertensive subjects who do not take medication; group $03=14$ non-hypertensive patients. Mean age was 52.7 years. All subjects in this study were sedentary and did not have the habit of measuring blood pressure, specifically the group 02 and group 03.The blood pressure was measured three times before starting the body balance and extracted average (Table 2). The groups 02 were not treated with drugs because they knew they were hypertensive. They knew when they made registration in the program of physical activity and health.

\section{Instrument used}

The tests were conducted using an Electronic Baropodometer comprised of a modular platform by Physical Support Italy. This device is comprised of platinum electronic sensors covered with an alveolar captor that recognizes plantar support information while preserving natural mobility. Image acquisition is accurate, instantaneous, reproducible and non-invasive. The Modular Electronic Baropodometer documents the analyses as images of plantar pressure points, front-back swaying, and side-to-side swaying (the latter two in centimeters)

\section{Data acquisition}

Swaying of the subjects' center of pressure was analyzed in two situations: bipodalic and monopodalicic, both static. Bipodalic stabilometry assessment was conducted with the subjects standing on the platform on both feet, with their arms hanging at their sides. The subjects were instructed to stand with their feet comfortably apart (approximately shoulder width), with arms relaxed at their sides.

Monopodalicic analysis was first performed with the subjects standing on their left feet, right knee bent and raised. Subsequently, the analysis was repeated on the other side. In all of the analyzed situations, the subjects were barefoot and performed the test first with their eyes open, then with eyes closed. In all cases, the measuring equipment was calibrated to 05 seconds for the procedures. The baropodometric assessments of the three groups were always performed in the morning, never later than 10:00 am. For the group of medicated hypertensive patients (HM), the assessments were performed 30 minutes after the subjects had taken their antihypertensive medications.

Assessments of body balance in all participating subjects were performed on three different days, respecting the same time (not exceeding at 10:00 in the morning). After completion of three evaluations of each subject draw the general average (Tables 2, 3 and 4).

\section{Results}

Table 1 shows the results of measurements of blood pressure of subjects belonging to three groups in the form of general average measured three times before each body balance.

As the results shown in Tables 2,3 and 4, we find that the values for the oscillations are higher for the group 01 in bipodalic posture and monopodalic axes $\mathrm{Y}$ and $\mathrm{X}$. This shows that the subjects varied group 01 in the anterior / posterior and lateral side with risk of falls than the other groups. The group 02 also showed higher values with respect to body balance in the $\mathrm{Y}$ and $\mathrm{X}$ axes, but the levels were higher in the $\mathrm{X}$ axis. This indicates that they swung more towards lateral side with higher risk of falls. With the results presented was quite evident that high blood pressure can cause higher than normal risk of falls for people, however, the increased risk of falls has been demonstrated for the group 01 that makes use of antihypertensive medication.

\begin{tabular}{|l|l|l|l|}
\hline SUBJECTS & SBP & DBP & $H R$ \\
\hline HM & 20,9 & 11,9 & 155 \\
\hline H & 15,8 & 10,9 & 100 \\
\hline NH & 12,0 & 8,0 & 85 \\
\hline
\end{tabular}

$\mathrm{HM}$ - hypertensive and taking medication

$\mathrm{H}$ - hypertensive and not taking medication

$\mathrm{NH}$ - non-hypertensive

Table 1: Mean blood pressure and heart rate of subjects belonging to the three groups submitted to bipodalic and monopodalicic baropodometric assessment.

\begin{tabular}{|l|l|}
\hline VARIABLES & OVERALL AVERAGES \\
\hline Eyes Open & 0.41 \\
\hline EOXHM & 0.40 \\
\hline EOYHM & 0.31 \\
\hline EOXH & 0.35 \\
\hline EOYH & 0.12 \\
\hline EOXNH & 1.15 \\
\hline EOYNH & \\
\hline & \\
\hline Eyes Closed & 0.30 \\
\hline ECXHM & 0.40 \\
\hline ECYHM & 0.34 \\
\hline ECXH & 0.38 \\
\hline ECYH & 0.14 \\
\hline ECXNH & 0.16 \\
\hline ECYNH & \\
\hline
\end{tabular}

Table 2: Averages in centimeters extracted from the stabilometric assessments of bipodalic posture in Hypertensive patients under the influence of antihypertensive medication $(\mathrm{HM})$, Hypertensive subjects not taking medication $(\mathrm{H})$ and NonHypertensive subjects $(\mathrm{NH})$, eyes open (EO) and closed $(\mathrm{EC})$, axes $\mathrm{X}$ and $\mathrm{Y}$. Overall averages in centimeter. 


\begin{tabular}{|l|l|}
\hline VARIABLES & OVERALL AVERAGES \\
\hline Eyes Open & 1.55 \\
\hline EOXHM & 1.38 \\
\hline EOYHM & 0.81 \\
\hline EOXH & 1.39 \\
\hline EOYH & 0.35 \\
\hline EOXNH & 0.28 \\
\hline EOYNH & \\
\hline Eyes Closed & 6.21 \\
\hline ECXHM & 4.32 \\
\hline ECYHM & 4.99 \\
\hline ECXH & 1.70 \\
\hline ECYH & 1.65 \\
\hline ECXNH & 1.05 \\
\hline ECYNH & \\
\hline
\end{tabular}

Table 3: Averages in centimeters extracted from the stabilometric assessments of monopodalicic posture in Hypertensive patients under the influence of antihypertensive medication (HM), Hypertensive subjects not taking medication $(\mathrm{H})$ and Non-Hypertensive subjects $(\mathrm{NH})$, eyes open $(\mathrm{EO})$ and closed $(\mathrm{EC})$, axes $\mathrm{X}$ and $\mathrm{Y}$, right foot. Overall averages in centimeter.

\begin{tabular}{|l|l|}
\hline VARIABLES & OVERALL AVERAGES \\
\hline Eyes Open & \\
\hline EOXHM & 8.50 \\
\hline EOYHM & 5.25 \\
\hline EOXH & 5.80 \\
\hline EOYH & 3.60 \\
\hline EOXNH & 2.25 \\
\hline EOYNH & 2.75 \\
\hline Eyes Closed & \\
\hline ECXHM & 8.64 \\
\hline ECYHM & 4.93 \\
\hline ECXH & 5.85 \\
\hline ECYH & 3.68 \\
\hline ECXNH & 1.98 \\
\hline ECYNH & 1.93 \\
\hline
\end{tabular}

Table 4: Averages in centimeters extracted from the stabilometric assessments of monopodalicic posture in Hypertensive patients under the influence of antihypertensive medication (HM), Hypertensive subjects not taking medication $(\mathrm{H})$ and Non-Hypertensive subjects $(\mathrm{NH})$, eyes open $(\mathrm{EO})$ and closed $(\mathrm{EC})$, axes $\mathrm{X}$ and $\mathrm{Y}$, left foot. Overall averages in centimeter.

\section{Statistical analysis}

Statistical analysis used analysis of variance, two-factor ANOVA without replication $\mathrm{p}<0.05$. The results were significant for the group with hypertensive and hypertensive medication for bipodalic posture. There was no significant difference in variables between the bipodalic posture open and closed eyes. There was significant difference in the posture monopodalic right foot to the hypertensive group on drugs in the $\mathrm{X}$ and $\mathrm{Y}$ axes eyes closed and the hypertensive group in the $\mathrm{X}$ axis right foot eyes closed. The results were also significant for posture monopodalic left foot to the hypertensive group with hypertensive medication and $\mathrm{X}$-axis eyes open and eyes closed. There was no significant difference between open and closed eyes. The differences were always in relation to the axes $\mathrm{X}$ and $\mathrm{Y}$.

\section{Discussion}

When oscillate the $\mathrm{Y}$ axis move your body like a pendulum in the anterior / posterior, and when the $\mathrm{X}$ axis oscillates in directions lateral / side. When this oscillation is increased for some reason we are more resilient to falls, injuries and fracture [5]. The neuromuscular activity that prevents the person from losing balance and falling is the body's automatic posture control. As the individual sways along the $\mathrm{X}$ and $\mathrm{Y}$ axes, his or her visual, somatosensory and vestibular receptors detect those variations and generate compensatory responses in the adequate muscles (Dietz, 1992). One of the mechanisms that cause higher rates of falling among elderly people is likely to be a decline in the ability to detect and control body swaying [12].

According to Bankoff $[3,4]$, in addition to these factors, elderly people also suffer the effects of high arterial blood pressure and of antihypertensive drugs, which most of them take. Therefore, they are also under the influence of these medications, especially in the first hour after ingestion.

The results presented herein show higher values for hypertensive patients who take antihypertensive drugs (group 01) and for nonmedicated hypertensive subjects (group 02). The subjects with normal blood pressure (group 03) swayed much less than the other two groups, irrespective of which variable was analyzed (bipodalic or monopodalicic posture, eyes open or closed). Thus, it was shown quite clearly that arterial blood pressure and antihypertensive drugs have an influence on body balance in static postures.

In addition to the evidence presented herein, we cannot disregard the role and function of Baroreceptors with regard to body posture, as these receptors are also affected by high blood pressure and by the ingestion of antihypertensive medications.

The results shown by the subjects' assessments baropodométricas groups of 01 and 02 , which are higher values when compared with the group 03 reflect the responses of two questions in relation to feelings of loss of balance to get out of bed, and the group on 01 feelings of loss of balance after an hour of ingesting the product antihiertensivo which responded to these feelings increased after the intake of antihypertensive medication.

We did not find in the research literature on the influence of antihypertensive drugs on baroreceptors, however, through the results is possible that antihypertensive drugs have some effects on the baroreceptors than the control of body posture and body balance.

Ricci et al. [14] report that during aging, the ability of sensory systems send information to the central nervous system is compromised, either by the presence of disease, either by use of medicine. Regarding the use of drugs, it is reported that the concomitant use of five or more drugs is associated with increased risk of dizziness in elderly individuals. In this study, the use of drugs by the elderly women was a reality, especially with regard to antihypertensive drugs and diuretics, and other pharmacological groups.

Among these co-morbidities are arterial hypertension, which promotes changes in the heart and blood vessels sanguíneos, may cause balance disorders due to peripheral and / or central system vestibular, due to the deficit in the supply of oxygen and nutrients to maintain celular integrity. In fact, vascular changes increase blood viscosity, which reduces capillary blood flow and, consequently, tissue hypoxia occurs, which leads to complaints or even loss of their hearing portadores [13].

Although our subjects are not elderly, we believe that our research will contribute towards prevention for the future of these individuals who suffer from hypertension and antihypertensive medication use.

\section{Conclusion}

In the present study showed that antihypertensive medication 
(Captopril) after 30 minutes intake associated with severe hypertension (group 01 - Table 1) caused a significant increase in body sway changing body balance. Also, this study evidenced that high blood pressure levels (group 02-table 1) increases body sway changing the body balance. In both groups, this change may cause risk of falls, specifically the group 01 . There is need for more information on hypertensive patients with or without drugs on the care that they should have in relation to body balance and consequently on the risk of falls to rise from bed in the morning, when they walk, up and down stairs and other.

\section{References}

1. Bankoff ADP, Pelegrinotti IL, Moraes AC, Galdi EHG, Moreira ZW, et al. (1992) Analisis poddometrico de los atletas de levantamiento de peso mediante la técnica vídeo-podometrica. Annals Olympic Congress 1: 18.

2. Bankoff ADP, Bekedorf RG, Scmidt A, Ciol P, Zamai CA, et al. (2006) Analise do equilíbrio corporal estatico através de um baropodometro eletronico. Revista Conexoes 4.

3. Bankoff ADP, Bekedorf R (2007) Bases neurofisiológicas do equilíbrio corporal. Buenos Aires: Revista Ef deportes, Ano 11.

4. Bankoff ADP (2007) Morfologia e cinesiologia aplicada ao movimento humano. Rio de Janeiro: Guanabara Koogan.

5. Bankoff ADP (2011) Study on body balance in hypertensive patients. Annals European Congress Sport and Science I.

6. Barela JA (2000) Estrategias de controle em movimentos complexos: ciclo percepcao-acao no controle postural. Revista Paulista de Educacao Física 3: 79-88.
7. Bear MF, Connors BW, Paradiso MA (2002) Neurociências: desvendando o sistema nervoso. Porto Alegre: Artmed, $2^{\text {nd }}$ edition.

8. Costa SS da, Cruz OLM, Oliveira JAA de (1994) Otorrinolaringologia: princípios e prática. Porto Alegre: Artes Médias.

9. Guidetti G (1997) Diagnosi e terapiai del disturbi dell'equilibrio. $2^{\text {nd }}$ edition, Roma, Marropense.

10. Guyton \& Hall, Tratado de Fisiologia Médica, Rio de Janeiro, Guanabara Koogan Dietz V (2011) Human neuronal controlo e automatic functional movement: Interaction between central programs and afferent input. $12^{\mathrm{a}}$ edition, Physiological Reviews 72: 33-69.

11. Hennemam, E O Cerebelo, Mountcastle, Vernon B, Rio de Janeiro, et al (1982) Fisiologia médica, $13^{\text {th }}$ edition.

12. Horak FB, Shupert CL, Mirka A (1989) Components of postural dyscontrol in the elderly: A review. Neurobiology of Aging 10: 727-738.

13. Marchiori LLM, Melo JJ, Possete FLF, Correa AL (2010) Comparacao da frequencia de queixa de vertigem no idoso com e sem hipertensão arterial. Arq Int Otorrinolaringol 14: 456-460.

14. Ricci NA, Gazzola JM, Coimbra IB (2009) Sistemas sensoriais no equilíbrio corporal de idosos. Arq Bras Ciênc Saúde 34: 94-100.

15. Spirduso WW, Francis KL, Macrae PG Motor control, coordinations and skill.

16. Spirduso WW, Francis KL, Macrae PG (1995) Physical Dimensions of Aging Champaingn, Human Kinectics 152-183.

17. Zanardini FH, Zeigelboim BS, Jurkiewicz AL, Marques JM, Martins-Bassetto J (2007) Reabilitacao vestibular em idosos com tontura. Pro-Fono 19: 177-184. 